\title{
Interleukin-6 Neutralization by Antibodies Immobilized at the Surface of Polymeric Nanoparticles as a Therapeutic Strategy for Arthritic Diseases
}

\author{
Ana Cláudia Lima, ${ }^{\dagger,+}$ Cristina Cunha, ${ }^{\ddagger} \S$ Agostinho Carvalho, ${ }^{\ddagger}$ Helena Ferreira, $^{\dagger,}$ \\ and Nuno M. Neves $*^{* \dagger, t, \perp_{(0)}}$ \\ $\lceil 3$ B’s Research Group-Biomaterials, Biodegradables and Biomimetics, University of Minho, Headquarters of the European Institute \\ of Excellence on Tissue Engineering and Regenerative Medicine, AvePark, 4805-017 Barco, Guimarães, Portugal \\ ${ }^{\ddagger}$ ICVS/3B’s-PT Government Associate Laboratory, 4805-017 Braga/Guimarães, Portugal \\ ${ }^{\S}$ Life and Health Sciences Research Institute (ICVS), School of Health Sciences, University of Minho, Campus de Gualtar, 4710-057 \\ Braga, Portugal \\ ${ }^{\perp}$ The Discoveries Centre for Regenerative and Precision Medicine, Headquarters at University of Minho, Avepark $4805-017$ Barco, \\ Guimarães, Portugal
}

ABSTRACT: Arthritic diseases are disabling conditions affecting millions of patients worldwide. Pro-inflammatory cytokines, particularly interleukin-6 (IL-6), plays a crucial role in inflammation and cartilage destruction. Although the beneficial effects of antibody therapy, its efficacy is limited. Therefore, this work proposes the immobilization of antibodies at the surface of biodegradable polymeric nanoparticles (NPs) to capture and neutralize IL-6. Our system is intended to protect, extend and enhance the therapeutic efficacy after delivery. Chitosan-hyaluronic acid NPs are synthesized as a
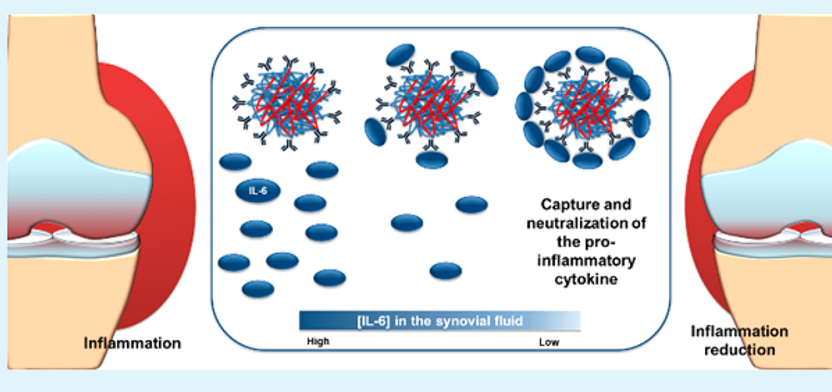
stable monodisperse population. After determining the maximum immobilization capacity $(10 \mu \mathrm{g} / \mathrm{mL})$, the capture ability was confirmed. Biological assays demonstrate the NPs cytocompatibility with human articular chondrocytes (hACs) and human macrophages. hACs stimulated with macrophage conditioned medium shows the beneficial role of IL-6 capture and neutralization. Biofunctionalized NPs exhibit a prolonged action and stronger efficacy than the free antibody. In conclusion, this system can be an effective and long lasting treatment for arthritic diseases.

KEYWORDS: arthritic diseases, pro-inflammatory cytokine interleukin-6, biodegradable polymeric nanoparticles, anti-IL-6 antibody immobilization, IL-6 capture and neutralization

\section{INTRODUCTION}

Arthritic diseases are inflammatory joint disorders, associated with synovitis and articular cartilage destruction. The most common forms of arthritis are osteoarthritis (OA) and rheumatoid arthritis (RA). ${ }^{1}$ OA, a local degenerative joint disease, is the leading cause of morbidity and disability in the elderly, affecting around $10 \%$ of men and $18 \%$ of women over 60 years of age. ${ }^{2}$ In contrast to OA, RA is a systemic autoimmune disease that usually involves multiple joints, affecting $0.3-1.0 \%$ of the general population. ${ }^{2}$

Even though joint damage in $\mathrm{OA}$ and $\mathrm{RA}$ proceeds via different pathways, in both the normal balance of extracellular matrix (ECM) is disrupted and shifts toward degradation. ${ }^{3}$ Cartilage disruption is associated with an increase of the levels of pro-inflammatory cytokines such as tumor necrosis factor- $\alpha$ (TNF- $\alpha$ ) and interleukins (IL, particularly IL- $1 \beta$ and IL-6), mainly produced by mononuclear cells, chondrocytes or synoviocytes. ${ }^{1}$ These cytokines increases the production of catabolic factors and down-regulates the anabolic mediators. 4
Hence, pro-inflammatory cytokines up-regulates injurious enzymes, especially matrix metalloproteinases. Simultaneously, they inhibit the production of their physiological regulators, stimulate the production of nitric oxide, and hinder the synthesis of ECM components such as collagen type II and aggrecan.

IL-6 is a key mediator in the pathophysiology of OA and RA, as it regulates a wide range of fundamental biological activities, including acute-phase responses, inflammation, and immune responses. ${ }^{6}$ Indeed, $\mathrm{OA}$ and RA patients present high concentrations of this pleiotropic cytokine, ${ }^{7}$ and many efforts are being made to create biosensors to monitor IL- 6 secretion in vivo. ${ }^{8}$ In addition, higher levels of IL-6 in OA was found to be a significant predictor of superior risk of cartilage loss and reduced response to treatment. ${ }^{9}$ Thus, strategies targeting IL-6

Received: January 25, 2018

Accepted: April 3, 2018

Published: April 3, 2018 
Scheme 1. Schematic Illustration of the Biofunctionalized NPs Role in Arthritis Treatment: (A) Production of the Biofunctionalized Polymeric NPs and (B) Inflammation Reduction in the Synovial Fluid after the Neutralization of IL-6 by the $\mathrm{NPs}^{a}$

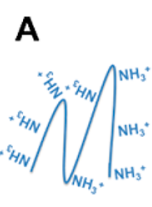

Ch
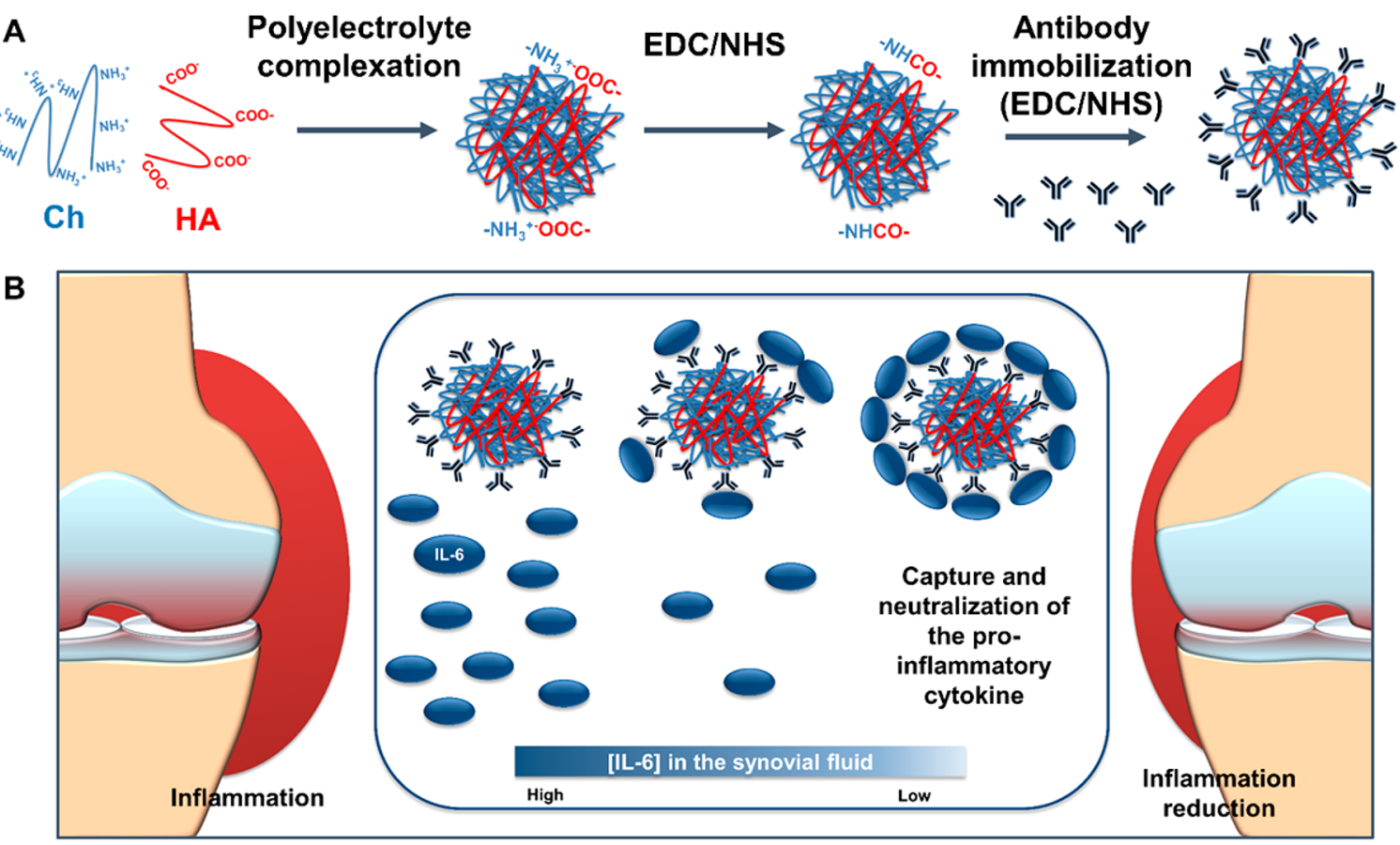

${ }^{a}$ Abbreviations: Ch, chitosan; HA, hyaluronic acid; EDC, ethyl-3-(3-(dimethylaminopropyl)carbodiimide; NHS, N-hydroxysuccinimide.

or its receptors are promising treatments for arthritis diseases. ${ }^{10}$ The first humanized anti-IL-6 receptor antibody, tocilizumab, has demonstrated its outstanding clinical efficacy and tolerable safety profile in phase III clinical trials for RA patients, resulting in its worldwide approval to treat moderate-to-severe active RA. This successful approach led to the development of other IL-6 inhibitors, including fully human anti-IL-6 receptor mAb (sarilumab, sirukumab, and olokizumab). ${ }^{11}$ This cytokine is being also considered the most interesting new target for OA treatment with clinical trials currently in progress [ClinicalTrials.gov Identifier: NCT02477059].

Although these treatments seem very attractive, systemic injection of biological agents are associated with serious side effects, such as risk of infection, administration reactions, congestive heart failure, demyelinating diseases, hyperlipidemia, among other conditions that affect patient health. ${ }^{12}$ In this sense, intra-articular (IA) injections offers several benefits by achieving high local bioavailability, reducing systemic exposure and requiring lower doses. ${ }^{13,14}$ However, because of the rapid clearance of antibodies by the synovium, the therapy has limited efficacy. Hence, there is an unmet need for the development of new effective approaches, with prolonged efficacy and reduced side effects.

Nanoparticles (NPs) are promising approaches to solve limitations of conventional therapies. ${ }^{14}$ The unique properties of NPs make them highly attractive for the design of novel modalities for arthritis treatment. Nanoscale features can be used to protect the therapeutic agent from degradation and to have targeted and controlled delivery, which improves drug efficacy, reduces the dosage and significantly reduces the side effects. Actually, polymeric NPs are one of the most studied strategies for nanomedicine. ${ }^{15}$ Polymers are widely used as building blocks, due to the flexible design based on functionalization, macromolecular synthesis methods, and polymer diversity. Regarding degradation properties, biodegradable polymeric NPs are highly preferred for medical applications, providing outstanding bioavailability, stability, compatibility and controlled release. ${ }^{16}$ In this work, naturalderived polymers were used, namely, chitosan ( $\mathrm{Ch}$ ) and hyaluronic acid (HA). They possess a high level of functional groups, such as amino $\left(\mathrm{NH}_{2}\right)$ and carboxylic acid $(\mathrm{COOH})$ groups, that can be further modified and functionalized with other polymers, cross-linkers, or biomolecules. ${ }^{17,18} \mathrm{Ch}$, the second most abundant polysaccharide in nature, is particularly attractive due to its advantages, such as noncytotoxicity, low immunogenicity, high stability, and reasonable cost. ${ }^{19,20}$ Although there are some studies reporting $\mathrm{Ch}$ as vaccine adjuvant, ${ }^{21}$ the capacity to promote cellular immunity is related with the deacetylation degree of the polymer. ${ }^{22}$ Indeed the deacetylation degree and immunogenicity are inversely correlated in this biomaterial. Therefore, in this work, Ch with a high degree of deacetylation was used to avoid any immunogenicity. HA is a natural component of the ECM of articular cartilage and synovial fluid. Because of the interaction with CD44 receptors of the cells, especially chondrocytes, HA plays an important role on cartilage function. ${ }^{23}$ Nonetheless, HA physicochemical and biological properties depend on its molecular weight $(\mathrm{MW}){ }^{24}$ High $\mathrm{MW}$ HA displays antiinflammatory and immune-suppressive properties, whereas low MW HA is a potent pro-inflammatory molecule. It has been reported that HA with MW of $700-6000 \mathrm{kDa}$ are the best suited for cartilage repair. ${ }^{19}$

The aim of this study was to develop a carrier intended for IA administration and allowing the capture and neutralization of IL-6, a crucial pro-inflammatory mediator in arthritic joints (Scheme 1). Ch and HA were used to produce biofunction- 
alized NPs with anti-IL-6 antibody immobilized at NPs' surface. The maximum immobilization of antibody and the capture capability was assessed. NPs cytocompatibility was validated by their culturing with human articular chondrocytes (hACs) and human macrophages. Our system was also validated by stimulating hACs with macrophage conditioned medium, and then treating with biofunctionalized NPs or the free antibody. Considering the drawbacks of the current treatments, we hypothesized that this strategy offers a maximum therapeutic effect of the immobilized antibodies, avoiding unnecessary exposure to healthy tissues and systemic side-effects.

\section{EXPERIMENTAL SECTION}

Materials. Ch with a MW of $150 \mathrm{kDa}$ and $95 \%$ of deacetylation degree was purchased from Heppe Medical Chitosan $\mathrm{GmbH}$ (Germany). HA with a MW of $750 \mathrm{kDa}$ was bought from Lifecore Biomedical (USA). Mouse monoclonal anti-IL-6 antibody and human IL-6 full length protein was purchased from Abcam (UK). Alexa Fluor 594 donkey antimouse IgG, Roswell Park Memorial Institute (RPMI)1640 media and Fetal Bovine Serum (FBS) were purchased from Thermo Fisher Scientific (USA). Human IL-6 Standard ABTS ELISA Development Kits and human Fibroblast Growth Factor (bFGF) was acquired from Peprotech (USA). CD14 MicroBeads and recombinant human granulocyte macrophage colony-stimulating factor (GM-CSF) was obtained from Miltenyi Biotec (USA). All other reagents were purchased from Sigma-Aldrich (USA).

NPs Preparation. Ch-HA NPs were prepared by polyelectrolyte complexation of both natural-based polyelectrolytes. Briefly, Ch was dissolved in $1 \%(\mathrm{v} / \mathrm{v})$ acetic acid, while HA was dissolved in ultrapure water, overnight at room temperature. Both solutions were filtered through a $0.22 \mu \mathrm{m}$ pore membrane. The NPs formation occurred spontaneously when the HA solution was added dropwise at $1 \mathrm{~mL} /$ min rate to the Ch solution under strong magnetic stirring $(600 \mathrm{rpm})$. Different initial polymers concentration $(0.25,0.5$, and $1 \mathrm{mg} / \mathrm{mL})$ and $\mathrm{pH}$ values $(3,4,5,6$ and 7$)$ were used to evaluate the influence of these parameters on the properties of the NPs.

During preparation, NPs were stabilized through carbodiimide chemistry. 1-ethyl-3-(3-(dimethylaminopropyl)carbodiimide (EDC)/ $\mathrm{N}$-hydroxysuccinimide (NHS) reagents were dissolved in 0.1 M MES buffer ( $\mathrm{pH} 4.7$ ) with $0.9 \%(\mathrm{w} / \mathrm{w}) \mathrm{NaCl}$. Five different EDC/NHS ratios were tested, namely $400 / 100,100 / 400,200 / 200,50 / 200$, and 200/50 mM

For fluorescence biological assays, $200 \mu \mathrm{L}$ of fluorescein isothiocyanate (FITC, $2 \mathrm{mg} / \mathrm{mL}$ in ethanol/water, 1:10) was added to the Ch solution before the NPs formation.

To remove unreacted compounds, the NPs were washed twice with ultrapure water by centrifugation $\left(30 \mathrm{~min}, 4000 \mathrm{rpm}\right.$ at $\left.20^{\circ} \mathrm{C}\right)$ using Vivaspin $300 \mathrm{kDa}$ Filter Units (Fisher Scientific). To avoid NPs aggregation, glucose at $2 \mathrm{mg} / \mathrm{mL}$ was added before centrifugation. ${ }^{25}$

NPs Characterization. Size Distribution and Zeta Potential Measurements. The size and polydispersity index (PDI) of the produced NPs were assessed by dynamic light scattering (DLS) and the zeta potential was determined by laser Doppler microelectrophoresis using a Zetasizer Nanoseries ZS equipment (Malvern Instruments, Portugal). The measurements were performed at $25{ }^{\circ} \mathrm{C}$ using samples diluted in ultrapure water $(1: 20 ; \mathrm{v} / \mathrm{v})$.

Stability Studies. For $\mathrm{pH}$ stability assessment, the $\mathrm{pH}$ was increased until 7.4 using $\mathrm{NaOH} 1 \mathrm{M}$. For storage stability, the NPs suspensions were kept at $4{ }^{\circ} \mathrm{C}$ under static conditions. During the experimental time ( 6 months), it was determined the size, PDI and zeta potential, as just described.

NPs Morphology. Morphological analysis of the developed Ch-HA NPs was performed by scanning electron microscopy (SEM) and atomic force microscopy (AFM). Prior to analysis, Ch-HA NPs were diluted in water $(1: 20 ; \mathrm{v} / \mathrm{v})$ and disposed into the surface of a glass slide for air-dry. For SEM analysis, the NPs were sputter-coated with palladium (EM ACE600, LEICA) and analyzed using High-Resolution Field Emission Scanning Electron Microscope (Auriga Compact,
ZEISS). AFM measurements were performed using a MultiMode STM microscope controlled by a NanoScope III from Digital Instruments system, operating in tapping mode at a frequency of $1 \mathrm{~Hz}$.

Antibody Immobilization Determination. The anti-IL-6 antibody was immobilized at the surface of the optimized Ch-HA NPs. To determine the NPs' maximum immobilization capacity, a range of primary antibody concentrations were tested (from 5 to $20 \mu \mathrm{g} / \mathrm{mL}$ ). First, the anti-IL-6 antibody was activated with a solution of 50/200 $\mathrm{mM}$ EDC/NHS in $0.1 \mathrm{M}$ MES buffer for $15 \mathrm{~min}$. Then, the NPs were incubated with the activated anti-IL- 6 antibody, overnight at $4{ }^{\circ} \mathrm{C}$. To remove the unbound antibody, the biofunctionalized NPs were washed twice by centrifugation, as previously described.

To determine the degree of anti-IL- 6 antibody immobilization, the biofunctionalized NPs were incubated with the secondary antibody Alexa Fluor 594 solution for $1 \mathrm{~h}$ at room temperature. As negative control, NPs without immobilized antibody were used $(0 \mu \mathrm{g} / \mathrm{mL})$. After centrifugation, the fluorescence of the unbound secondary antibody (in supernatant) were determined using an excitationemission wavelengths of $590 / 20-645 / 40 \mathrm{~nm}$, respectively, in a microplate reader (Synergie HT, Bio-Tek). The concentration of the anti-IL-6 antibody at the NPs surface corresponds to the difference between the initial and unbound secondary antibody.

IL-6 Capturing. Ch-HA NPs biofunctionalized with anti-IL-6 antibody $(5-20 \mu \mathrm{g} / \mathrm{mL})$ were incubated with $1.25 \mu \mathrm{g} / \mathrm{mL}$ of human IL-6 full length protein, overnight at room temperature. After centrifugation, the supernatants were collected and the unbound IL6 was assessed using the ELISA Development Kit. The amount of IL-6 captured by the biofunctionalized NPs corresponds to the difference between the initial and unbound amount of the added cytokine.

Biological Assays. Isolation and Cell Culture. hACs were isolated from knee cartilage samples collected from arthroplasties surgeries biopsies. Samples were obtained through the cooperation agreement between Centro Hospitalar do Alto Ave, Guimarães, Portugal, and 3B's Research Group, and after informed donor consent. Cells were isolated by enzymatic digestion, according to a previously described protocol. ${ }^{26}$ hACs cells were cultured in Dulbecco's modified Eagle's medium (DMEM), supplemented with 10\% FBS, 10 mM HEPES buffer, L-lanyl-L-glutamine, MEM nonessential amino acids, 100 units/ $\mathrm{mL}$ of penicillin, $100 \mu \mathrm{g} / \mathrm{mL}$ of streptomycin, and $10 \mathrm{ng} / \mathrm{mL}$ human bFGF, and incubated at $37{ }^{\circ} \mathrm{C}$ in a humidified $5 \% \mathrm{CO}_{2}$ atmosphere.

The human monocytic cell line THP-1 was maintained in complete RPMI, containing RPMI-1640 media supplemented with $2 \mathrm{mM} \mathrm{L}$ glutamine, 100 units $/ \mathrm{mL}$ of penicillin, $100 \mu \mathrm{g} / \mathrm{mL}$ of streptomycin, 10 mM HEPES buffer, and 10\% FBS.

Human monocyte-derived macrophages were generated from peripheral blood mononuclear cell (PBMCs). Buffy coats from healthy donors were obtained after written informed consent at the Hospital de Braga, Braga, Portugal. Briefly, PBMCs were enriched from buffy coats by density gradient using Histopaque-1077. Cells present in the enriched mononuclear fraction were washed twice in PBS and resuspended in RPMI-1640 culture medium with $2 \mathrm{mM}$ glutamine and $2 \mathrm{~g} / \mathrm{L} \mathrm{NaHCO}_{3}$ supplemented with $10 \%$ human serum, 100 units $/ \mathrm{mL}$ of penicillin, $100 \mu \mathrm{g} / \mathrm{mL}$ of streptomycin, and $10 \mathrm{mM}$ HEPES buffer. Monocytes were then separated by positive selection using magnetically labeled CD14 MicroBeads on a MiniMACS separator. Isolated monocytes were resuspended in complete RPMI medium and seeded at a concentration of $10^{6}$ cells $/ \mathrm{mL}$ in 24-well plates for 7 days in the presence of $20 \mathrm{ng} / \mathrm{mL}$ of GM-CSF. Acquisition of macrophage morphology was confirmed by visualization in a BX61 microscope (Olympus, Japan).

Cell Seeding. For hACs seeding, cells $\left(5 \times 10^{4}\right.$ cells $\left./ \mathrm{mL}\right)$ were added to tissue culture polystyrene (TPCS) coverslips in 24-well plates. After cell attachment during $5 \mathrm{~h}$, culture medium was added to a final volume of $1 \mathrm{~mL}$. Different concentrations of sterilized Ch-HA NPs were added to hACs subsequently to $24 \mathrm{~h}$ of incubation. NPs were sterilized by UV treatment for $30 \mathrm{~min}$.

For the induction of THP- 1 cell differentiation, cells $\left(10^{6}\right.$ cells $\left./ \mathrm{mL}\right)$ were seeded in cRPMI with $100 \mathrm{nM}$ phorbol 12-myristate-13-acetate (PMA) for $24 \mathrm{~h}$. After incubation, nonattached cells were removed by aspiration, and the adherent cells were washed three times with 

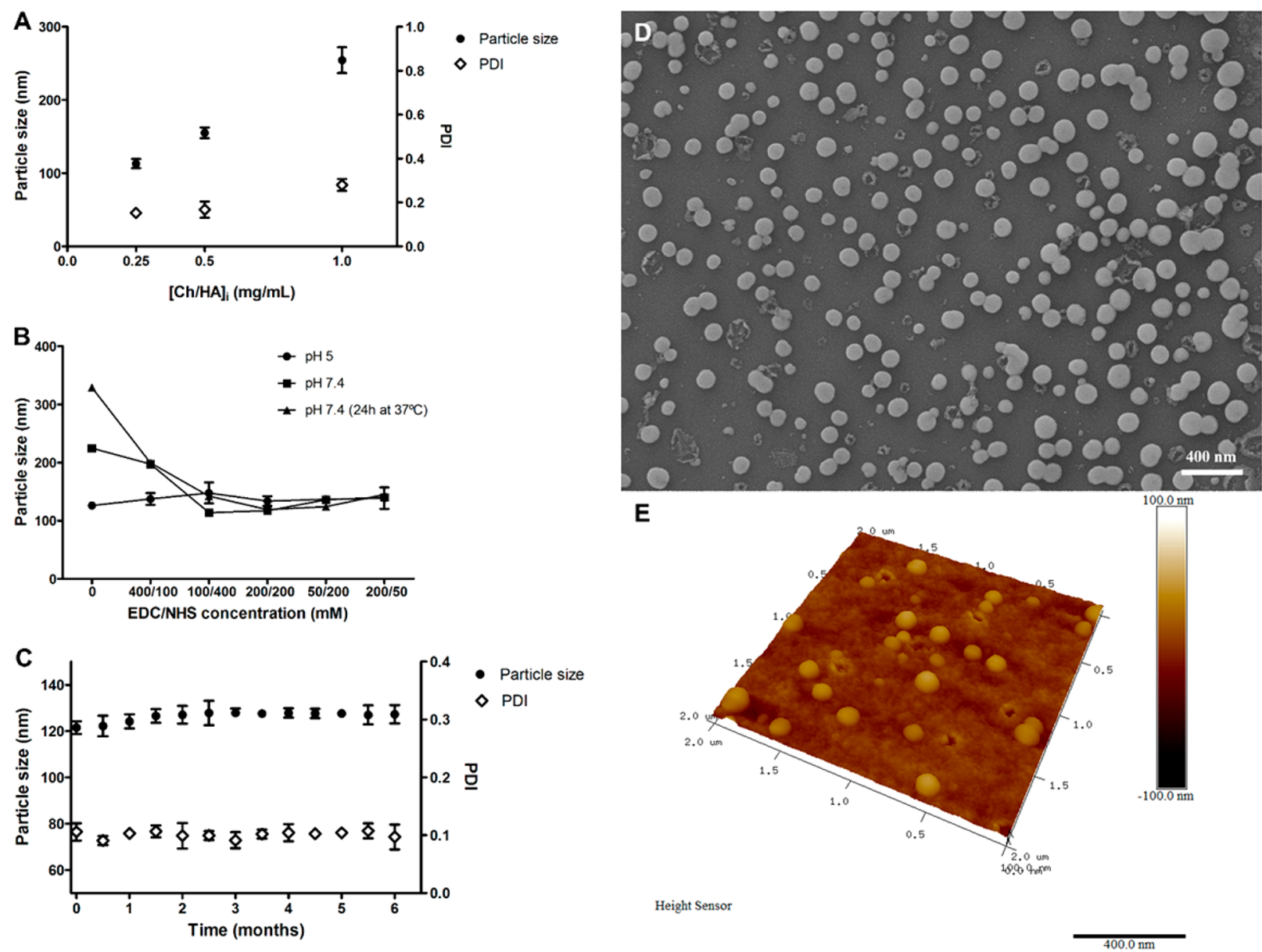

Figure 1. (A) Particle size and PDI of Ch-HA NPs obtained for different initial concentrations of Ch and HA, at pH 5. (B) Influence of EDC/NHS concentration on the particle size at $\mathrm{pH} 5$ and 7.4. (C) Stability evaluation of NPs kept in water at $4{ }^{\circ} \mathrm{C}$ for 6 months. (D) SEM and (E) AFM micrographs of the produced Ch-HA NPs.

cRPMI. To ensure reversion of cells to a resting macrophage phenotype before stimulation, cells were incubated for an additional $48 \mathrm{~h}$ in cRPMI without PMA. For stimulation and retrieval of conditioned media, cells were further incubated for $24 \mathrm{~h}$ with $100 \mathrm{ng} /$ $\mathrm{mL}$ of lipopolysaccharide in fresh media and the supernatants were collected and stored at $-80^{\circ} \mathrm{C}$. IL- 6 production by cells was assessed in the supernatants by commercial ELISA. Then, Ch-HA NPs were added at different concentrations.

Regarding the human primary macrophages, after 7 days in the presence of GM-CSF, culture medium was replaced and different concentrations of Ch-HA NPs were added.

Cells cultured without NPs (only with culture medium) were used as control. After 1, 2, 3, and 7 days of culture with NPs, the different samples in triplicate were washed with sterile PBS and analyzed regarding cell viability (MTS assay), cell proliferation (DNA quantification), total protein synthesis and SEM analyses.

Cell Viability. The metabolic activity of cells treated or not with different concentrations of Ch-HA NPs was determined by MTS assay (CellTiter 96 Aqueous One Solution, Promega), according to the instructions of the manufacturer. Briefly, a mixture of culture medium, without FBS and phenol red, and MTS reagent (5:1 volume ratio) were added to each well. Samples were incubated for $3 \mathrm{~h}$ at $37^{\circ} \mathrm{C}$ in a humidified $5 \% \mathrm{CO}_{2}$ atmosphere. The absorbance was read in triplicate at $490 \mathrm{~nm}$, using a microplate reader (Synergie HT, Bio-Tek).

Cell Proliferation. Cell proliferation was assessed using a fluorimetric dsDNA quantification kit (Quant-iT, PicoGreen, Molecular Probes, Invitrogen). First, cell samples were transferred to Eppendorf tubes containing $1 \mathrm{~mL}$ of ultrapure water and frozen at -80 ${ }^{\circ} \mathrm{C}$ until further analysis. Prior to DNA quantification, samples were defrosted and sonicated for $15 \mathrm{~min}$. DNA standards were prepared at concentrations ranging from 0 to $2 \mu \mathrm{g} / \mathrm{mL}$ in ultrapure water. To each well of a white opaque 96-well plate (Falcon) were added $28.7 \mu \mathrm{L}$ of sample or standard $(\mathrm{n}=3), 71.3 \mu \mathrm{L}$ of PicoGreen solution, and 100 $\mu \mathrm{L}$ of Tris-EDTA (TE) buffer. The plate was incubated for $10 \mathrm{~min}$ in the dark, and the fluorescence of each sample was measured in a microplate reader (Synergie HT, Bio-Tek), using an excitation wavelength of $485 \mathrm{~nm}$ and an emission wavelength of $528 \mathrm{~nm}$. DNA concentration of the samples was inferred from the standard curve.

Total Protein. Total protein content was quantified using a Micro BCA protein assay kit (Pierce, Thermo Scientific), according to the manufacturer's instructions. Briefly, samples were collected in triplicate as described above. Standards were prepared in ultrapure water in concentrations ranging from 0 to $40 \mu \mathrm{g} / \mathrm{mL}$. Then, $150 \mu \mathrm{L}$ of samples or standards in triplicate and $150 \mu \mathrm{L}$ of working reagent were added to each 96-well plate. The plate was sealed and incubated for $2 \mathrm{~h}$ at 37 ${ }^{\circ} \mathrm{C}$. Then, the absorbance was measured at $562 \mathrm{~nm}$ using a microplate reader (Synergie HT, Bio-Tek). Protein concentration was inferred from the standard curve.

SEM Analyses. SEM was used to analyze the morphology of cells in the presence of Ch-HA NPs. Briefly, cells were fixed with $2.5 \%$ glutaraldehyde and kept at $4{ }^{\circ} \mathrm{C}$. Dehydration was performed using increasing concentrations of ethanol $(10 \%, 20 \%, 40 \%, 60 \%, 80 \%, 90 \%$, $95 \%$, and $100 \%)$. Then, the samples were sputter-coated (EM ACE600, LEICA) with a thin layer $(8-12 \mathrm{~nm})$ of palladium and analyzed by High-Resolution Field Emission Scanning Electron Microscope (Auriga Compact, ZEISS). Microphotographs were recorded at $5 \mathrm{kV}$ with magnifications of 200, 1000, and 10000X.

NPs Internalization. For internalization assays, hACs were seeded at a concentration of 20000 cells per well on $\mu$-slides (Ibidi) for 
confocal microscopy analysis. Ch-HA NPs functionalized or not with the anti-IL-6 antibody were added at a concentration of $50 \mu \mathrm{g} / \mathrm{mL}$ to the cultured cells. After $12 \mathrm{~h}$, cells were fixed with $10 \%$ formalin in PBS and stored at $4{ }^{\circ} \mathrm{C}$. Then, samples were stained (between each step samples were washed three times with PBS): 1) cell membranes were permeated with Triton X-100 (0.2\%) for $5 \mathrm{~min}$; 2) nonspecific proteins were blocked with $3 \%$ bovine serum albumin for $30 \mathrm{~min} ; 3$ ) the cytoskeleton was staining with phalloidin $(0.25 \mu \mathrm{g} / \mathrm{mL})$ and cell nuclei labeled with DAPI $(1 \mu \mathrm{g} / \mathrm{mL})$ during $15 \mathrm{~min}$. Images of fluorescent-labeled cells and NPs were obtained by using excitation wavelengths of $405 \mathrm{~nm}$ (DAPI), $488 \mathrm{~nm}$ (FITC labeled NPs) and 561 $\mathrm{nm}$ (phalloidin). Images were acquired using a laser scanning confocal microscopy imaging system (TCS SP8, Leica).

Biofunctionalized NPs Capturing Ability of IL-6. hACs were seeded as previously described. After cell attachment, hACs were stimulated for $24 \mathrm{~h}$ with monocyte-derived macrophage conditioned medium containing $500 \mathrm{pg} / \mathrm{mL}$ of IL-6. hACs cultured without macrophage conditioned medium (only culture medium) were used as controls. Three different conditions were tested: (1) no treatment, (2) treatment with biofunctionalized NPs presenting a concentration of anti-IL-6 antibody equal to $1 \mu \mathrm{g} / \mathrm{mL}$, and (3) treatment with soluble anti-IL-6 antibody at a concentration of $1 \mu \mathrm{g} / \mathrm{mL}$. After $1,3,7$, and 14 days, samples were collected and evaluated regarding cell viability, proliferation, total protein synthesis and SEM analysis as previously described. The amount of IL- 6 in the supernatants was assessed by ELISA. During the time of experiment $300 \mu \mathrm{L}$ of fresh media was added each 3 days, but no media was removed to keep the NPs and the conditioned media in contact with the cells.

IL-6 Quantification. For the quantification of the IL-6, human sandwich IL-6 ELISA Kit was performed according to the manufacturer procedure. ABTS liquid substrate was added to each well and color development was assessed by measuring the absorbance at 405 and $650 \mathrm{~nm}$, in a microplate reader (Synergie HT, Bio-Tek). The IL-6 concentration was inferred from the standard curve.

Statistical Analyses. Data are presented as the mean \pm standard deviation of at least three independent assays. Statistical analyses were performed using GraphPad Prism Software. First, a Shapiro-Wilk test was used to establish the assumption of data normality. Since data not followed a normal distribution, a nonparametric test was used (Kruskal-Wallis test) followed by Dunn's test. $P<0.01$ was considered statistically significant.

\section{RESULTS}

Characterization of Ch-HA NPs. Ch-HA NPs were successfully prepared by polyelectrolyte complexation. The influence of the initial polymer concentration and $\mathrm{pH}$ values on size, PDI and zeta potential of Ch-HA NPs are shown in Figure $1 \mathrm{~A}$ and Table 1, respectively. Both particle size and PDI increased with the increase of the concentration of $\mathrm{Ch}$ and $\mathrm{HA}$

Table 1. Influence of $\mathrm{pH}$ Values on the Diameter, Polydispersity Index (PDI), and Zeta Potential of Ch-HA $\mathrm{NPs}^{a}$

\begin{tabular}{ccccc}
\multicolumn{3}{c}{ solution $\mathrm{pH}$} & & \\
\cline { 1 - 1 } Ch & HA & size $(\mathrm{nm})$ & PDI & zeta potential $(\mathrm{mV})$ \\
3 & & $859.1 \pm 427.6$ & $0.66 \pm 0.26$ & $5.77 \pm 0.58$ \\
4 & & $1134.0 \pm 139.1$ & $0.16 \pm 0.19$ & $7.10 \pm 2.24$ \\
$\mathbf{5}$ & $\mathbf{5}$ & $\mathbf{1 2 1 . 8} \pm \mathbf{2 . 4}$ & $\mathbf{0 . 1 1} \pm \mathbf{0 . 0 1}$ & $\mathbf{2 5 . 1 2} \pm \mathbf{1 . 8 6}$ \\
6 & & $430.5 \pm 82.6$ & $0.31 \pm 0.18$ & $5.87 \pm 4.43$ \\
7 & & $3337.0 \pm 640.4$ & $0.78 \pm 0.31$ & $-19.68 \pm 3.31$ \\
5 & 4 & $128.2 \pm 13.5$ & $0.20 \pm 0.04$ & $16.33 \pm 2.40$ \\
& 6 & $121.3 \pm 6.7$ & $0.19 \pm 0.04$ & $16.96 \pm 5.38$ \\
& 7 & $117.8 \pm 4.29$ & $0.17 \pm 0.08$ & $18.00 \pm 0.99$
\end{tabular}

${ }^{a_{T}}$ The $\mathrm{pH}$ of the solutions used to produce the selected NPs are highlighted in the table. polymers, within a linear range relationship. Concerning the aim of this study, it was selected the condition that originates smaller NPs $(0.25 \mathrm{mg} / \mathrm{mL})$ to obtain a higher surface area for enlarged biofunctionalization. Regarding the influence of $\mathrm{pH}$ (Table 1), it can be inferred that the initial $\mathrm{pH}$ of $\mathrm{Ch}$ solution has a huge influence on particle size and PDI, in contrast with the initial $\mathrm{pH}$ of HA solution. The same behavior was observed for zeta potential measurements. The initial $\mathrm{pH}$ of the $\mathrm{Ch}$ solution has a significant impact on the zeta potential, presenting a higher value at $\mathrm{pH} 5$. The $\mathrm{pH}$ of the HA solution has no impact over the zeta potential, but higher values were also found for a $\mathrm{pH}$ value of 5 . Since we aimed to produce monodisperse NPs with higher stability, we selected $\mathrm{pH} 5$ for both $\mathrm{Ch}$ and HA solutions. Additionally, it was observed that adding glucose to the NPs suspension before centrifugation avoids their aggregation $(121.8 \pm 2.4 \mathrm{~nm}, 0.11 \pm 0.01$ of PDI and $178.8 \pm 51.1 \mathrm{~nm}, 0.24 \pm 0.08$ of PDI in the presence or in the absence of glucose, respectively, after centrifugation). Although the Ch-HA NPs were stable in water, the particle size and PDI increased at $\mathrm{pH}$ 7.4. In order to increase the NPs stability at physiological $\mathrm{pH}$, carbodiimide chemistry (EDC/ NHS) was tested. As shown in Figure 1B, the optimal concentrations of EDC/NHS for stabilization were $50 \mathrm{mM}$ / $200 \mathrm{mM}$, since it is required lower concentrations of reagents to have the same effect over NPs size distribution.

Storage stability was also assessed, and as shown in Figure 1C the produced NPs were stable during time without a significant increase of size and PDI for at least 6 months.

From SEM and AFM analyses (Figure 1D and E, respectively), it was possible to observe that Ch-HA NPs presented a spherical shape with dimensions around $130 \mathrm{~nm}$, which is in agreement with the DLS measurements.

Optimization of Antibody Immobilization at the NPs Surface. Anti-IL-6 antibody was covalently immobilized at the NPs surface using the same chemistry previously described. To quantify the amount of primary antibody immobilized at the NPs surface, an indirect method was used, based on the measurement of the fluorescence of the unbound secondary antibody (Figure 2). Higher fluorescence values of secondary

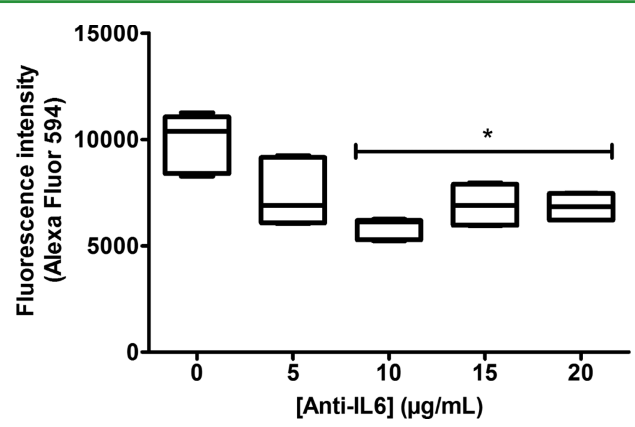

Figure 2. Box plot of anti-IL-6 antibody immobilization at 0 to $20 \mu \mathrm{g} /$ $\mathrm{mL}$ concentrations. Asterisk $(*)$ denotes significant differences $(p<$ $0.01)$ compared to control $(0 \mu \mathrm{g} / \mathrm{mL})$.

antibody correspond to lower concentrations of immobilized anti-IL-6 antibody. As can be observed in Figure 2, concentrations above $10 \mu \mathrm{g} / \mathrm{mL}$ displayed significantly lower values of fluorescence intensity than control $(0 \mu \mathrm{g} / \mathrm{mL})$. Moreover, these concentrations did not display significantly differences between them. Therefore, the maximum immobilization capacity of anti-IL-6 antibody is $10 \mu \mathrm{g} / \mathrm{mL}$. After this 
point, the NPs surface becomes saturated and the fluorescence intensity reaches a plateau.

Afterward antibody immobilization, the biofunctionalized NPs presented $132.05 \pm 2.58 \mathrm{~nm}$ of diameter, $0.12 \pm 0.01$ of PDI and $+20.07 \pm 2.10 \mathrm{mV}$ of zeta potential. Additionally, the NPs remained stable.

Capture of IL-6. To confirm the ability of the primary antiIL-6 antibody immobilized at the NPs' surface to capture and neutralize IL-6, a human full length recombinant IL-6 protein was added at $1.250 \mu \mathrm{g} / \mathrm{mL}$ to the biofunctionalized NPs. The amount of unbound IL-6 determined in NPs without functionalization (Table 2) revealed their ineffectiveness of

Table 2. Amount of the Human Recombinant IL-6 Captured by Biofunctionalized NPs

$\begin{array}{cccc}\begin{array}{c}\text { initial [anti-IL6 } \\ \text { antibody] } \\ (\mu \mathrm{g} / \mathrm{mL})\end{array} & \begin{array}{c}\text { [IL-6] unbound } \\ (\text { supernatant }) \\ (\mu \mathrm{g} / \mathrm{mL})\end{array} & \begin{array}{c}\text { [IL-6] capture } \\ \text { by NPs } \\ (\mu \mathrm{g} / \mathrm{mL})\end{array} & \text { \% capture } \\ 0 & 1.245 \pm 0.025 & & \\ 5 & 0.068 \pm 0.007 & 1.182 \pm 0.007 & 94.56 \pm 0.56 \\ 10 & 0.028 \pm 0.020 & 1.222 \pm 0.020 & 97.79 \pm 1.6 \\ 15 & 0.067 \pm 0.017 & 1.183 \pm 0.017 & 94.64 \pm 1.36 \\ 20 & 0.057 \pm 0.018 & 1.193 \pm 0.018 & 95.44 \pm 1.44\end{array}$

capturing IL-6. For biofunctionalized NPs, the maximum capture $(1.222 \pm 0.020 \mu \mathrm{g} / \mathrm{mL})$ was achieved with an initial antibody concentration of $10 \mu \mathrm{g} / \mathrm{mL}$, which comprises around $98 \%$ of capture. No significant differences were found for higher initial concentrations of anti-IL-6 antibody.

Biological Assays. NPs Cytocompatibility. To use Ch-HA NPs as a platform of antibody carrying to treat arthritic diseases, it was performed an assessment of their potential toxicity for: (1) hACs, (2) human monocyte-like cell line, THP-1, and (3) human primary macrophages. hACs isolated from diseased knee arthroplasties have a phenotype associated with arthritic diseases, being a relevant model to assess any toxic interaction. Macrophages were also used since they represent a suitable model to assess the cytocompatibility of NPs with the immune system.

Different biological assays were conducted to assess cell viability (MTS assay), proliferation (DNA quantification), total protein synthesis and morphology (SEM) after 1, 2, 3, and 7 days of culture.

For hACs a wide range of NPs concentration (10-500 $\mu \mathrm{g} /$ $\mathrm{mL}$ ) was tested. Even though cell viability (Figure 3A) was not affected, considering the cell proliferation at NPs concentrations above $50 \mu \mathrm{g} / \mathrm{mL}$, there was a significantly decrease compared to the control. Nonetheless, SEM analyses confirm that the cell morphology was not affected by NPs (Figure 4A). From these results, we can infer that the maximum NPs concentration that does not have a harmful effect to the cells is $50 \mu \mathrm{g} / \mathrm{mL}$. For NPs internalization assessment, hACs were exposed during $12 \mathrm{~h}$ to NPs, subjected or not to
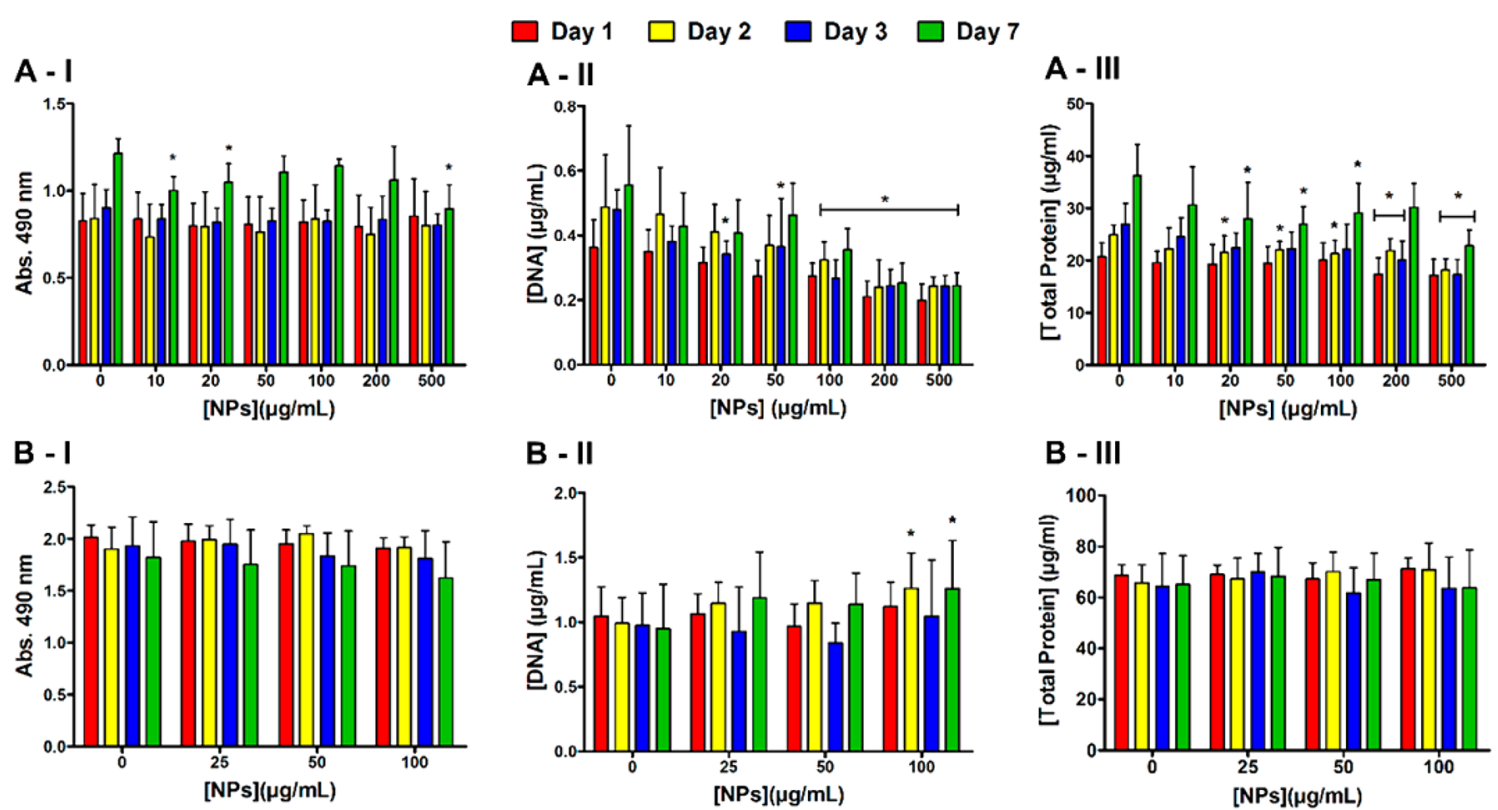

B - II
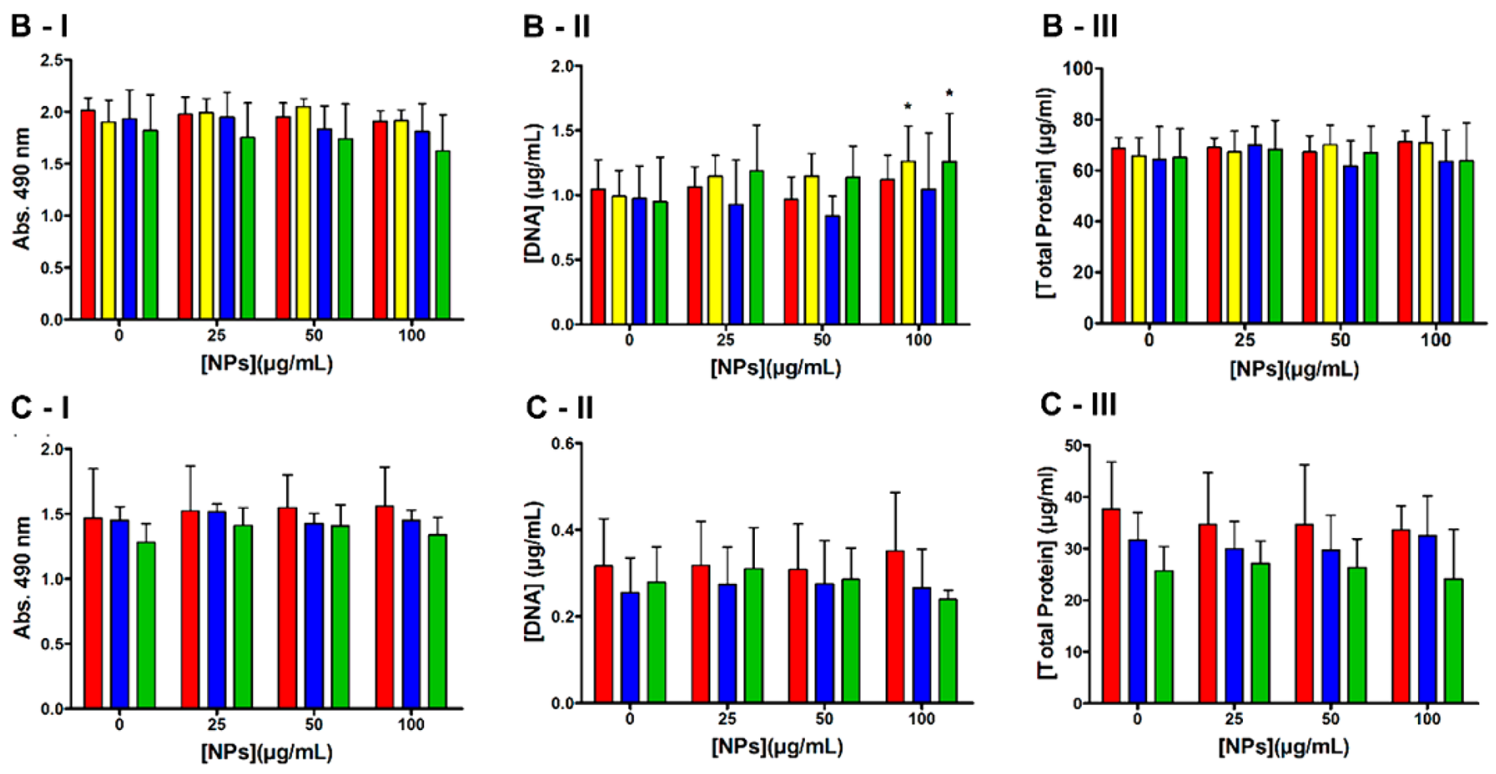

Figure 3. Biological performance of the (A) hACs, (B) THP-1 cell line, and (C) primary human macrophages cultured with different concentrations of Ch-HA NPs: (I) cell viability, (II) cell proliferation and (III) total protein synthesis after 1, 2, 3, and 7 days of culture. Asterisk (*) denotes significant differences $(p<0.01)$ compared to the control $(0 \mu \mathrm{g} / \mathrm{mL})$. 

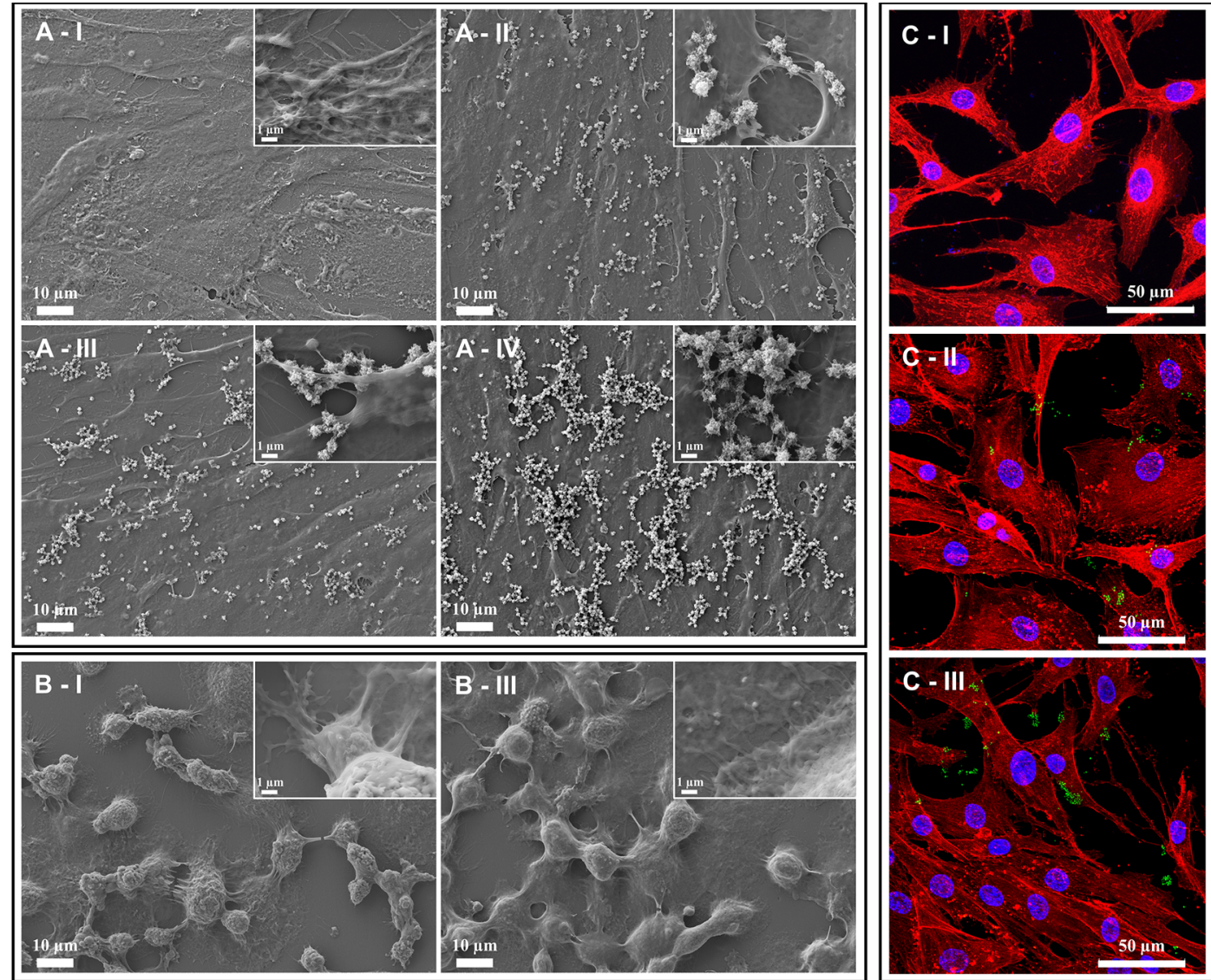

Figure 4. SEM micrographs of Ch-HA NPs cultured with (A) hACs or (B) THP-1 cells in the absence (control, I) and in the presence of NPs at different concentrations: (II) 20, (III) 50, and (IV) $100 \mu \mathrm{g} / \mathrm{mL}$. Confocal microscopy images of hACs (C): (I) control, (II) NPs, and (III) biofunctionalized NPs, being the NPs green (FITC), nuclei blue (DAPI), and the cytoskeleton red (phalloidin).

biofunctionalization, at a concentration of $50 \mu \mathrm{g} / \mathrm{mL}$ (Figure 4C). Comparing the results of the samples with NPs to the control, it seems that the hACs do not internalize NPs.

Taking into account the previous results, for THP-1 cell line (Figure $3 \mathrm{~B}$ and $4 \mathrm{~B}$ ) and human primary macrophages (Figure 3C) three different NPs concentrations (25, 50, and $100 \mu \mathrm{g} /$ $\mathrm{mL}$ ) were tested. Since there were no significant differences between the NPs and the control, it can be concluded that the NPs are not cytotoxic at these concentrations for those cells.

Evaluation of IL-6 Capture by Biofunctionalized NPs and Its Biologic Effects. To confirm the capacity of the primary anti-IL-6 antibody immobilized at the NPs' surface to capture and neutralize IL-6, hACs were stimulated with macrophage conditioned medium containing $500 \mathrm{pg} / \mathrm{mL}$ of IL-6, for $24 \mathrm{~h}$. Then, three different conditions were tested: (1) hACs without treatment (no treat), (2) treatment with biofunctionalized NPs (NPs $+\mathrm{Ab}$ ), and (3) treatment with soluble anti-IL-6 antibody $(\mathrm{Ab})$. hACs cultured without macrophage conditioned medium were used as controls $(\mathrm{Ctr})$.

Regarding the amount of unbound IL- 6 in the medium (Figure 5A), the results showed that macrophage conditioned medium had a huge impact on IL-6 production by cells, which corroborates the susceptibility to inflammation of hACs isolated from osteoarthritic patients. These cells produce around $8 \mathrm{ng} /$ $\mathrm{mL}$ of IL-6 without any stimulus. Given the macrophage conditioned medium, they increased in 85 to 190 times the amount of this cytokine ( 0.68 to $1.51 \mu \mathrm{g} / \mathrm{mL}$ at 1 and 14 days, respectively). Moreover, there was a higher reduction of free IL-6 in the medium with biofunctionalized NPs comparing to the soluble antibody. Therefore, the results confirmed the initial hypothesis that the primary antibody immobilized at the NPs' surface had a longer effect than the soluble antibody.

After hACs stimulation with macrophage conditioned medium there was a significant decrease in cell viability and DNA concentration comparatively to the control (Figure 5B and C). Alternatively, the condition with biofunctionalized NPs had an improvement in cell viability and proliferation, since there was no significant difference when compared with the control. Furthermore, this improvement was significantly higher in comparison with the soluble antibody, especially at 7 and 14 days. Despite these results, total protein concentration was almost the same for all conditions under evaluation (Figure $5 \mathrm{D})$.

The analyses of cell morphology (Figure 6) revealed that the stimulated cells showed altered morphology with cell shrinkage, especially after 14 days. As shown in Figure 6, hACs remained widely normal with the addition of functionalized NPs, while the addition of soluble antibody did not prevent cell shrinkage.

\section{DISCUSSION}

The aim of this study was to develop a carrier intended for local administration and allowing the capture and inactivation of a central pro-inflammatory mediator, IL-6, in arthritic joints. Ch and HA polysaccharides were used as the NPs building blocks. The backbone of $\mathrm{Ch}$ consists of glucosamine units, which has a high density of $\mathrm{NH}_{2}\left(\mathrm{p} K_{\mathrm{a}} \approx 6.5\right)$, giving to $\mathrm{Ch}$ its cationic nature. This property allows $\mathrm{Ch}$ to electrostatically bind with 
$\square$ Day $1 \square$ Day $3 \square$ Day $7 \square$ Day 14
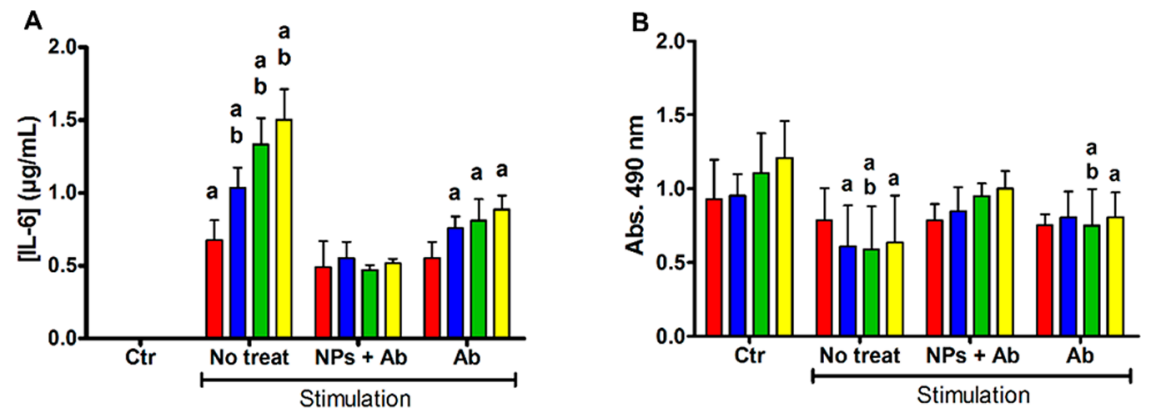

Conditions

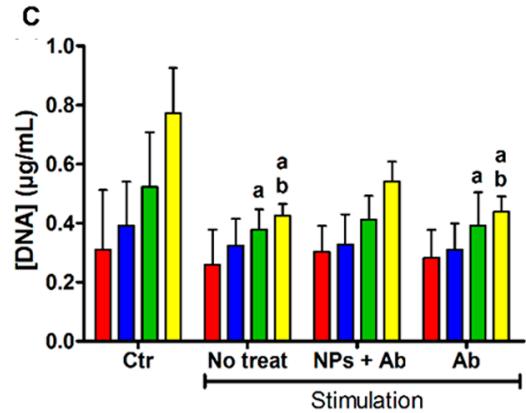

Conditions

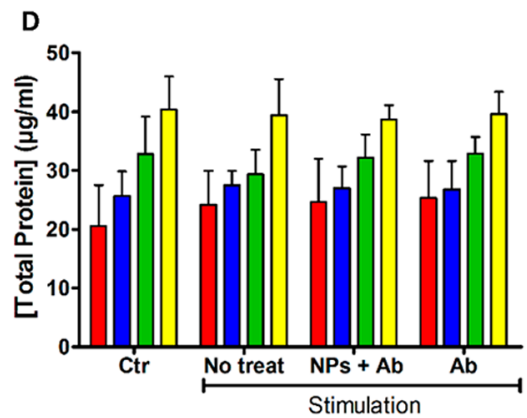

Conditions

Conditions

Figure 5. Biochemical performance of the stimulated hACs: (1) without stimulation (Ctr), (2) hACs without treatment (no treat), (3) treatment with biofunctionalized NPs (NPs + Ab), and (4) treatment with soluble antibody (Ab), and analyzed regarding (A) unbound IL-6 concentration, (B) cell viability, (C) cell proliferation, and (D) total protein synthesis. a denotes significant difference $(p<0.01)$ compared to the Ctr, and $\mathbf{b}$ denotes significant difference $(p<0.01)$ compared to NPs + Ab.
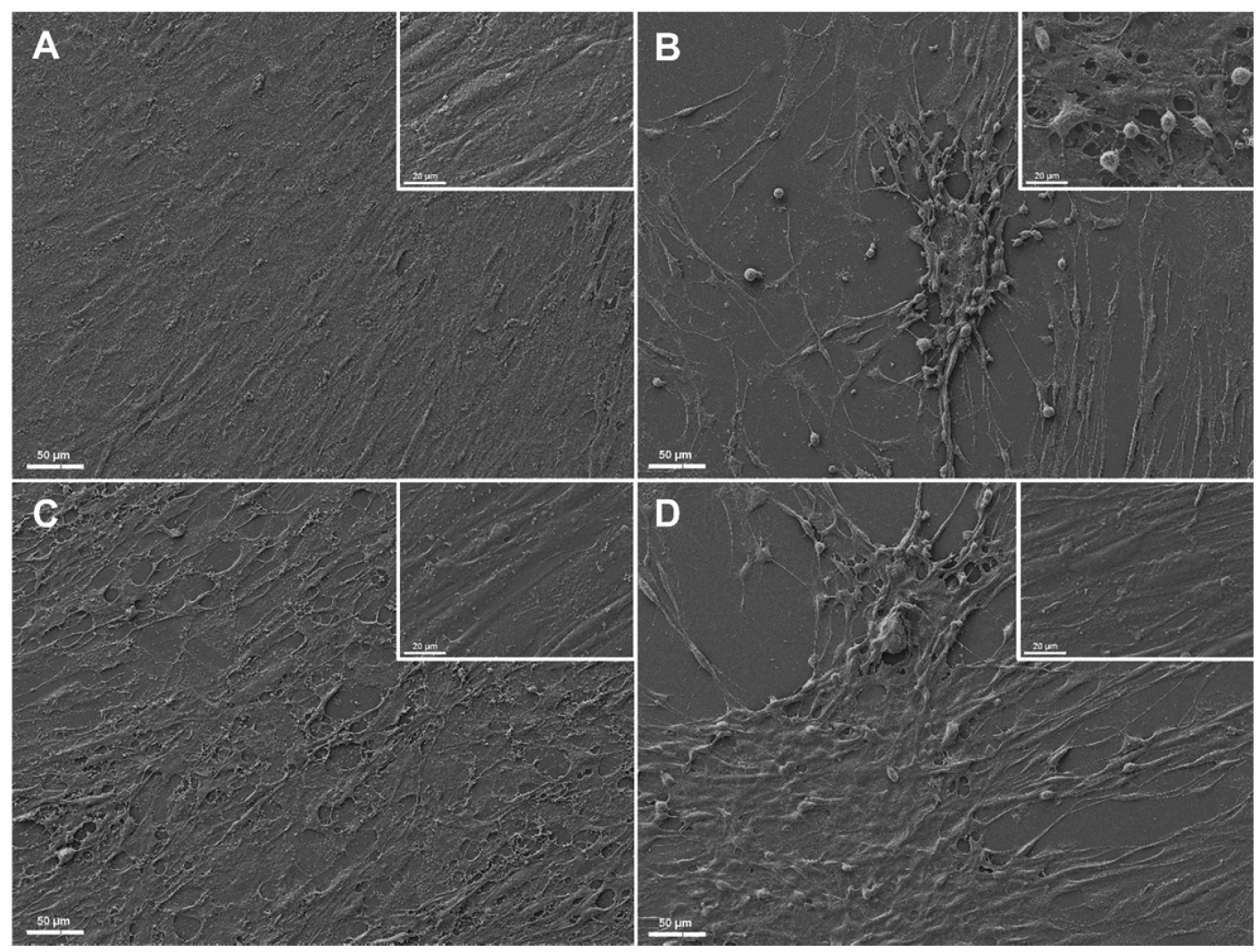

Figure 6. SEM micrographs of stimulated hACs: (A) control without stimulation, (B) stimulation without treatment, (C) biofunctionalized NPs, and (D) soluble Ab after 14 days of culture. Micrographs obtained after 7 days of culture are shown to evaluate the effect during time (small images). 
negatively charged molecules. $\mathrm{HA}$ is an anionic biopolymer containing glucuronic acid with $\mathrm{COOH}$ as functional groups $\left(\mathrm{pK}_{\mathrm{a}} 3-4\right)$, at a proportion of $1: 2$ comparing to $\mathrm{NH}_{2}$ of $\mathrm{Ch}$. These two functional groups were used to produce NPs by polyelectrolyte complexation. As in the literature, ${ }^{27,28}$ the initial polymer concentrations were optimized according to the experimental conditions and the aim of the work. Therefore, we selected $0.25,0.5$, and $1 \mathrm{mg} / \mathrm{mL}$. The concentration of $\mathrm{Ch}$ and HA was observed to affect the size and PDI of the resulting NPs. Additionally, different initial $\mathrm{pH}$ of the polymers solutions was tested to evaluate the impact of the protonation/ deprotonation of $\mathrm{NH}_{2}$ and $\mathrm{COOH}$ groups on the properties of the NPs. Indeed, the $\mathrm{pH}$ of the $\mathrm{Ch}$ solution has a strong impact in the particle size. $\mathrm{NH}_{2}$ groups of $\mathrm{Ch}$ are protonated at $\mathrm{pH} 5, \mathrm{NH}_{3}{ }^{+}$, which is necessary to interact with $\mathrm{COOH}$ groups of the $\mathrm{HA}$ that are deprotonated at $\mathrm{pH} 5\left(\mathrm{COO}^{-}\right)$. Therefore, at $\mathrm{pH} 5$ electrostatic interactions between the opposite charges can be established, resulting in NPs formation. ${ }^{29}$ However, those interactions are a reversible physical cross-linking. Consequently, due to the electrostatic interactions weakness of the NPs taking place at $\mathrm{pH} 7.4$ (physiological $\mathrm{pH}$ ) there is an increase of the NPs size.

Hence, cross-linkers are essential to increase $\mathrm{pH}$ stability and mechanical strength. ${ }^{30}$ In this work, EDC/NHS were used to catalyze the reaction between the $\mathrm{NH}_{2}$ of $\mathrm{Ch}$ and the $\mathrm{COOH}$ of HA to form amide bonds. ${ }^{31}$ The resulting NPs were stable at physiological $\mathrm{pH}$, even after $24 \mathrm{~h}$ at $37{ }^{\circ} \mathrm{C}$. This chemical reaction does not represent a problem in terms of cytotoxicity, since EDC/NHS chemistry is a zero-length cross-linker. ${ }^{32}$ Additionally, the only byproduct of the reaction, urea, is nontoxic, and as all products are water-soluble they are easily removed in the washing steps. Therefore, an absence of cytotoxicity is expected. Indeed, several works have being demonstrated the in vitro and in vivo cytocompatibility of EDC/NHS chemistry. ${ }^{33}$

Stable NPs with $121.8 \pm 2.4 \mathrm{~nm}$ of diameter, $0.11 \pm 0.01$ of PDI, and $+25.12 \pm 1.86 \mathrm{mV}$ of zeta potential were produced with $0.25 \mathrm{mg} / \mathrm{mL}$ of concentration of the initial polymers solutions, at $\mathrm{pH} \mathrm{5}$, and with $50 / 200 \mathrm{mM}$ of EDC/NHS concentration, after their centrifugation with glucose. NPs size and PDI significantly increased without the addition of this sugar to the NPs suspension. As reported for lyophilization, ${ }^{34}$ the centrifugation with glucose leads to the development of a layer around the NPs in the pellet, avoiding their aggregation when resuspended. From these results, it can be inferred that the NPs suspension are homogeneous in terms of size, since typically monodisperse suspensions have PDI values less than $0.2{ }^{35}$ As expected from the ratio of $\mathrm{NH}_{2} / \mathrm{COOH}(2: 1)$, the zeta potential of the produced NPs was positive. Recent reports have been described that cationic proteins and particles increase the retention of therapeutic agents in articular joints. ${ }^{36,37}$ Hence, it will be expectable higher retention in the target tissue of the developed NPs. Moreover, the value of zeta potential gives an indication of the NPs suspension stability. ${ }^{38}$ Higher absolute values of this parameter, give rise to stronger repellent electrostatic interactions between the NPs dispersed in water, which leads to a higher stability of the suspension. Guidelines classifying NP suspensions with zeta potential values of $\pm 0-10$ $\mathrm{mV}$ as highly unstable, $\pm 10-20 \mathrm{mV}$ as relatively stable, $\pm 20-$ $30 \mathrm{mV}$ as moderately stable, and $> \pm 30 \mathrm{mV}$ as highly stable. ${ }^{39}$ Regarding the value obtained around $+25 \mathrm{mV}$, it is possible to conclude that the NPs are moderately stable. Stability assays also corroborated the suspension stability, since they showed that NPs conserved their size distribution for at least 6 months, under the tested conditions.

After optimization of the process for NPs preparation, antiIL-6 antibody was immobilized at their surface using the same chemistry previously referred. In this case, the $\mathrm{COOH}$ groups of the antibodies reacted specifically with the $\mathrm{NH}_{2}$ groups present at the NPs' surface. The maximum concentration of antibody immobilized by NPs was obtained when it was used an initial anti-IL-6 antibody concentration of $10 \mu \mathrm{g} / \mathrm{mL}$. After this point, the values of the antibody immobilization reached a plateau, and despite the increment of antibody concentration, no significant differences were observed in its quantity on the NPs' surface. Moreover, it can be concluded that the immobilization of the antibody at the NPs' surface did not affect significantly the NPs properties.

Since the goal of the present study was to produce NPs for IL-6 neutralization, after the primary antibody immobilization, the cytokine capture capacity was assessed. The maximum binding ability was obtained for an initial concentration of antibody of $10 \mu \mathrm{g} / \mathrm{mL}$, which corresponds to the capture of $1.22 \pm 0.02 \mu \mathrm{g} / \mathrm{mL}$ of the protein added $(1.25 \mu \mathrm{g} / \mathrm{mL})$. Despite the increment of the anti-IL- 6 antibody concentration added to the NPs suspension, the biofunctionalized NPs neutralized equivalent amounts of the cytokine, which corroborates the maximum immobilization capacity of the anti-IL-6 antibody at NPs' surface, obtained for an initial antibody concentration of $10 \mu \mathrm{g} / \mathrm{mL}$.

To use Ch-HA NPs as a platform to treat arthritic diseases, an assessment of their potential toxicity for both chondrocytes and immune cells was performed. Ch-HA NPs in a concentration until $50 \mu \mathrm{g} / \mathrm{mL}$ did not present toxicity for hACs, THP-1 cells and human primary macrophages. For the hACs, higher amounts of NPs $(10-500 \mu \mathrm{g} / \mathrm{mL})$ were assessed and besides none of the concentrations had a huge impact in cell viability, for concentrations higher than $50 \mu \mathrm{g} / \mathrm{mL}$, the cell proliferation was negatively affected. These results can be explained by analyzing SEM micrographs, where it can be seen that at higher concentrations, the NPs form agglomerates around hACs that can inhibit cell spreading. Concerning the immune cells, the Ch-HA NPs were not cytotoxic under the tested conditions $(25,50$, and $100 \mu \mathrm{g} / \mathrm{mL})$. In summary, it is possible to conclude that Ch-HA NPs are cytocompatible for concentrations up to $50 \mu \mathrm{g} / \mathrm{mL}$.

Since inflammation had an important role in the pathological process of these diseases, it was investigated if the biofunctionalized NPs could avoid the negative impact of inflammation into human chondrocytes. hACs were stimulated with macrophage conditioned medium and three different conditions were tested: (1) hACs without treatment, (2) treatment with biofunctionalized NPs presenting a concentration of anti-IL-6 antibody equal to $1 \mu \mathrm{g} / \mathrm{mL}$, and (3) treatment with soluble anti-IL-6 antibody at a concentration of $1 \mu \mathrm{g} / \mathrm{mL}$. hACs cultured without macrophage conditioned medium (only culture medium) were used as controls (Ctr).

The IL- 6 of the conditioned media was quantified in order to ensure the presence of $500 \mathrm{pg} / \mathrm{mL}$ of IL-6, which is within the range of the IL- 6 levels found in the synovial fluid of OA and $\mathrm{RA}$ patients $(119.4 \pm 193.2$ and $354.7 \pm 1851.6 \mathrm{pg} / \mathrm{mL}$, respectively). ${ }^{40}$ This experiment showed that the macrophage conditioned medium has a huge impact in the hACs production of IL-6, since they increase in 85-190 times the amount of IL6 , when compared to the control. Additionally, it corroborates the susceptibility to inflammation of hACs isolated from 
osteoarthritic patients. The reduction of the interleukin amount obtained in the conditions with biofunctionalized NPs or with soluble antibody confirms the neutralization of IL-6 by the primary antibody, and consequently the reduction of its negative effects. Moreover, there was a higher reduction of IL-6 in the medium with biofunctionalized NPs comparing to the soluble antibody, which confirmed the initial hypothesis that the primary antibody immobilized at the NPs' surface had a longer effect than the soluble antibody.

A previous study demonstrated that the synovial fluid obtained from $\mathrm{OA}$ and RA patients led to altered cell morphology, to a highly significant decrease of vital chondrocytes and also activates the synthesis of proinflammatory cytokines in primary human chondrocytes. ${ }^{41}$ In the present work, we used macrophage conditioned medium to stimulate hACs, and observed similar effects, since there was a significant decrease in cell viability and DNA concentration, and cell morphology shift in the stimulation condition. Since the addition of the biofunctionalized NPs was able to reduce these effects (more than the free antibody), it was demonstrated that the antibody immobilized at the NPs' surface has a prolonged action and stronger efficacy than the free antibody. The antibody immobilization can increase its stability and reduce its degradation, explaining the prolonged effect observed. Therefore, the conjugation of antibodies to NPs combines the advantages of NPs support, with lower degradability, and longer half-life time and efficacy of the antibodies. Moreover, they retain the specific and selective recognition of the antigens to capture and neutralize them. ${ }^{42}$

In a recent study, anti-IL-6 antibodies were encapsulated into poly(lactic-co-glycolic acid) NPs to antagonize the effect of IL-6 locally in the heart, as a therapeutic procedure to prevent/ ameliorate organ ischemia-reperfusion injury. ${ }^{43}$ The localized delivery of anti-IL- 6 significantly reduced immune rejection of transplants with a lower amount administered, comparing with the systemic delivery. In this context, the covalent immobilization of anti-IL-6 into Ch-HA NPs' surface can be a viable and effective strategy to increase the antibody efficacy when injected locally in joint cavities, which can reduce the dosage and significantly avoid associated systemic side effects.

Although the controversy about the size necessary to retain longer the particles in the joint cavity, preclinical studies clearly demonstrate that NPs can be effective for IA delivery. ${ }^{44}$ The prescribed dose of anti-IL-6 in RA patients (for OA patients is not yet an available therapy) is around $8 \mathrm{mg} / \mathrm{kg} \mathrm{IV}$, which can be dramatically reduced using this system injected IA. Indeed, with $1 \mu \mathrm{g} / \mathrm{mL}$ of antibody immobilized in NPs the inflammatory scenario was significantly reduced. Furthermore, as the NPs are composed of well-known biodegradable polymers, they can be further degraded by biological processes, without any toxic effects for the cells, enabling subsequent treatments.

\section{CONCLUSION}

In the present work, we developed natural biodegradable polymeric NPs biofunctionalized with anti-IL-6 antibodies able to selectively capture and inactivate the pro-inflammatory cytokine IL-6. Because of the key role of IL-6 in arthritis, its effective neutralization by the NPs will reduce inflammation, leading to a possible decrease of swelling and pain in such diseases.

Current treatments present serious side effects and limited efficacy mainly because of the rapid clearance of antibodies by the body. Presently, to have an improvement in arthritis, higher doses, and extended periods of treatments are needed. Therefore, it is foreseeable that the developed NPs will overcome the limitations of the above-mentioned treatments, since they will increase the antibodies therapeutic efficacy as a result of their subcellular size, cytocompatibility, high functionalization, and stability, avoiding associated side effects. Indeed, these systems have enhanced efficacy and prolonged action in the capture and neutralization of IL- 6 when compared with the free antibody.

In conclusion, the biofunctionalized NPs are a valid approach for the local and sustained treatment of inflammatory arthritic diseases. Hence, the outcomes of this work have important implications for increasing the efficacy of currently available treatments, by prolonging the therapeutic action of the antibodies and avoiding most of their side effects. Those benefits will be further tested in relevant arthritis animal models.

\section{AUTHOR INFORMATION}

\section{Corresponding Author}

*E-mail: nuno@dep.uminho.pt.

\section{ORCID}

Nuno M. Neves: 0000-0003-3041-0687

\section{Author Contributions}

The manuscript was written through contributions of all authors. All authors have given approval to the final version of the manuscript.

\section{Notes}

The authors declare no competing financial interest.

\section{ACKNOWLEDGMENTS}

Authors acknowledge the financial support from FCT/MCTES (Portuguese Foundation for Science and Technology/Ministry of Science, Technology and Higher Education) and the FSE/ POCH (European Social Fund through the Operational Program of Human Capital), for the PhD scholarship PD/ $\mathrm{BD} / 11384 / 2015$ of A. C. Lima (PD/59/2013), the FCT for the grant of A. Carvalho (IF/00735/2014) and C. Carvalho (SFRH/BPD/96176/2013). Authors would also like to acknowledge FCT for the project PTDC/CTM-BIO/4388/ 2014-SPARTAN, and the Northern Portugal Regional Operational Programme (NORTE 2020), under the Portugal 2020 Partnership Agreement, through the European Regional Development Fund (FEDER) (NORTE-01-0145-FEDER000023-FROnTHERA and NORTE-01-0145-FEDER-000013PersonalizedNOS).

\section{REFERENCES}

(1) Roy, K.; Kanwar, R. K.; Kanwar, J. R. Molecular targets in arthritis and recent trends in nanotherapy. Int. J. Nanomed. 2015, 10, 54075420 .

(2) Woolf, A. D.; Pfleger, B. Burden of major musculoskeletal conditions. Bull. World Health Organ. 2003, 81 (9), 646-656.

(3) Pap, T.; Korb-Pap, A. Cartilage damage in osteoarthritis and rheumatoid arthritis-two unequal siblings. Nat. Rev. Rheumatol. 2015, 11 (10), 606-615.

(4) Martel-Pelletier, J.; Wildi, L. M.; Pelletier, J. P. Future therapeutics for osteoarthritis. Bone 2012, 51 (2), 297-311.

(5) Alcaraz, M. J.; Megias, J.; Garcia-Arnandis, I.; Clerigues, V.; Guillen, M. I. New molecular targets for the treatment of osteoarthritis. Biochem. Pharmacol. 2010, 80 (1), 13-21. 
(6) Kimura, A.; Kishimoto, T. IL-6: regulator of Treg/Th17 balance. Eur. J. Immunol. 2010, 40 (7), 1830-1835.

(7) Santos Savio, A.; Machado Diaz, A. C.; Chico Capote, A.; Miranda Navarro, J.; Rodríguez Alvarez, Y.; Bringas Pérez, R.; Estévez del Toro, M.; Guillen Nieto, G. E. Differential expression of proinflammatory cytokines IL-15Ralpha, IL-15, IL-6 and TNFalpha in synovial fluid from Rheumatoid arthritis patients. BMC Musculoskeletal Disord. 2015, 16, 51.

(8) Qi, M.; Huang, J. W.; Wei, H.; Cao, C. M.; Feng, S. L.; Guo, Q.; Goldys, E. M.; Li, R.; Liu, G. Z. Graphene Oxide Thin Film with Dual Function Integrated into a Nanosandwich Device for in Vivo Monitoring of Interleukin-6. ACS Appl. Mater. Interfaces 2017, 9 (48), 41659-41668.

(9) Livshits, G.; Zhai, G.; Hart, D. J.; Kato, B. S.; Wang, H. Z.; Williams, F. M. K.; Spector, T. D. Interleukin-6 Is a Significant Predictor of Radiographic Knee Osteoarthritis The Chingford Study. Arthritis Rheum. 2009, 60 (7), 2037-2045.

(10) Adachi, Y.; Yoshio-Hoshino, N.; Nishimoto, N. The blockade of IL-6 signaling in rational drug design. Curr. Pharm. Des. 2008, 14 (12), $1217-1224$

(11) Tanaka, Y. O. A.; Kishimoto, T. Targeting of Interleukin-6 for the Treatment of Rheumatoid Arthritis: A Review and Update. Rheumatology: Current Research 2013, No. S4-002.

(12) Woodrick, R. S.; Ruderman, E. M. Safety of biologic therapy in rheumatoid arthritis. Nat. Rev. Rheumatol. 2011, 7 (11), 639-652.

(13) Iannitti, T.; Lodi, D.; Palmieri, B. Intra-articular injections for the treatment of osteoarthritis: focus on the clinical use of hyaluronic acid. Drugs R\&D 2011, 11 (1), 13-27.

(14) O’Mary, H.; del Rincón, I.; Cui, Z. Nanomedicine for IntraArticular Drug Delivery in Rheumatoid Arthritis. Curr. Med. Chem. 2016, 23 (23), 2490-2506.

(15) Banik, B. L.; Fattahi, P.; Brown, J. L. Polymeric nanoparticles: the future of nanomedicine. Wires Nanomed Nanobi 2016, 8 (2), 271299.

(16) Kumari, A.; Yadav, S. K.; Yadav, S. C. Biodegradable polymeric nanoparticles based drug delivery systems. Colloids Surf., B 2010, 75 (1), $1-18$

(17) Wen, Y. F.; Oh, J. K. Recent Strategies to Develop Polysaccharide-Based Nanomaterials for Biomedical Applications. Macromol. Rapid Commun. 2014, 35 (21), 1819-1832.

(18) Oliveira, C.; Costa-Pinto, A. R.; Reis, R. L.; Martins, A.; Neves, N. M. Biofunctional nanofibrous substrate comprising immobilized antibodies and selective binding of autologous growth factors. Biomacromolecules 2014, 15 (6), 2196-2205.

(19) Muzzarelli, R. A.; Greco, F.; Busilacchi, A.; Sollazzo, V.; Gigante, A. Chitosan, hyaluronan and chondroitin sulfate in tissue engineering for cartilage regeneration: a review. Carbohydr. Polym. 2012, 89 (3), 723-739.

(20) Grenha, A.; Gomes, M. E.; Rodrigues, M.; Santo, V. E.; Mano, J. F.; Neves, N. M.; Reis, R. L. Development of new chitosan/ carrageenan nanoparticles for drug delivery applications. J. Biomed. Mater. Res., Part A 2010, 92 (4), 1265-1272.

(21) Carroll, E. C.; Jin, L.; Mori, A.; Munoz-Wolf, N.; Oleszycka, E.; Moran, H. B. T.; Mansouri, S.; McEntee, C. P.; Lambe, E.; Agger, E. M.; Andersen, P.; Cunningham, C.; Hertzog, P.; Fitzgerald, K. A.; Bowie, A. G.; Lavelle, E. C. The Vaccine Adjuvant Chitosan Promotes Cellular Immunity via DNA Sensor cGAS-STING-Dependent Induction of Type I Interferons. Immunity 2016, 44 (3), 597-608.

(22) Patel, S.; Goyal, A. Chitin and Chitinase: Role in pathogenicity, allergenicity and health. Int. J. Biol. Macromol. 2017, 97, 331-338.

(23) Umerska, A.; Corrigan, O. I.; Tajber, L. Intermolecular interactions between salmon calcitonin, hyaluronate, and chitosan and their impact on the process of formation and properties of peptide-loaded nanoparticles. Int. J. Pharm. 2014, 477 (1-2), 102112.

(24) Litwiniuk, M.; Krejner, A.; Speyrer, M. S.; Gauto, A. R.; Grzela, $\mathrm{T}$. Hyaluronic Acid in Inflammation and Tissue Regeneration. Wounds: A Compendium of Clinical Research and Practice 2016, 28 (3), 78-88.
(25) Paiva, A. M.; Pinto, R. A.; Teixeira, M.; Barbosa, C. M.; Lima, R. T.; Vasconcelos, M. H.; Sousa, E.; Pinto, M. Development of noncytotoxic PLGA nanoparticles to improve the effect of a new inhibitor of p53-MDM2 interaction. Int. J. Pharm. 2013, 454 (1), 394402.

(26) Alves da Silva, M. L.; Costa-Pinto, A. R.; Martins, A.; Correlo, V. M.; Sol, P.; Bhattacharya, M.; Faria, S.; Reis, R. L.; Neves, N. M. Conditioned medium as a strategy for human stem cells chondrogenic differentiation. J. Tissue Eng. Regener. Med. 2015, 9 (6), 714-723.

(27) de la Fuente, M.; Seijo, B.; Alonso, M. J. Novel hyaluronic acidchitosan nanoparticles for ocular gene therapy. Invest. Ophthalmol. Visual Sci. 2008, 49 (5), 2016-2024.

(28) Lu, H. D.; Zhao, H. Q.; Wang, K.; Lv, L. L. Novel hyaluronic acid-chitosan nanoparticles as non-viral gene delivery vectors targeting osteoarthritis. Int. J. Pharm. 2011, 420 (2), 358-365.

(29) Denuziere, A.; Ferrier, D.; Damour, O.; Domard, A. Chitosanchondroitin sulfate and chitosan-hyaluronate polyelectrolyte complexes: biological properties. Biomaterials 1998, 19 (14), 1275-1285.

(30) Mavila, S.; Eivgi, O.; Berkovich, I.; Lemcoff, N. G. Intramolecular Cross-Linking Methodologies for the Synthesis of Polymer Nanoparticles. Chem. Rev. 2016, 116 (3), 878-961.

(31) Kang, M. L.; Ko, J. Y.; Kim, J. E.; Im, G. I. Intra-articular delivery of kartogenin-conjugated chitosan nano/microparticles for cartilage regeneration. Biomaterials 2014, 35 (37), 9984-9994.

(32) Yang, X. X.; Wang, X. Y.; Yu, F.; Ma, L. L.; Pan, X. H.; Luo, G. J.; Lin, S.; Mo, X. M.; He, C. L.; Wang, H. S. Hyaluronic acid/EDC/ NHS-crosslinked green electrospun silk fibroin nanofibrous scaffolds for tissue engineering. RSC Adv. 2016, 6 (102), 99720-99728.

(33) Ahmad, Z.; Shepherd, J. H.; Shepherd, D. V.; Ghose, S.; Kew, S. J.; Cameron, R. E.; Best, S. M.; Brooks, R. A.; Wardale, J.; Rushton, N. Effect of 1-ethyl-3-(3-dimethylaminopropyl) carbodiimide and $\mathrm{N}$ hydroxysuccinimide concentrations on the mechanical and biological characteristics of cross-linked collagen fibres for tendon repair. Regenerative biomaterials 2015, 2 (2), 77-85.

(34) Wang, Y. C.; Zheng, Y.; Zhang, L.; Wang, Q. W.; Zhang, D. R. Stability of nanosuspensions in drug delivery. J. Controlled Release 2013, 172 (3), 1126-1141.

(35) Panchal, J.; Kotarek, J.; Marszal, E.; Topp, E. M. Analyzing subvisible particles in protein drug products: a comparison of dynamic light scattering (DLS) and resonant mass measurement (RMM). AAPS J. 2014, 16 (3), 440-451.

(36) Bajpayee, A. G.; De la Vega, R. E.; Scheu, M.; Varady, N. H.; Yannatos, I. A.; Brown, L. A.; Krishnan, Y.; Fitzsimons, T. J.; Bhattacharya, P.; Frank, E. H.; Grodzinsky, A. J.; Porter, R. M. Sustained intra-cartilage delivery of low dose dexamethasone using a cationic carrier for treatment of post traumatic osteoarthritis. European cells \& materials 2017, 34, 341-364.

(37) Morgen, M.; Tung, D.; Boras, B.; Miller, W.; Malfait, A. M.; Tortorella, M. Nanoparticles for Improved Local Retention after IntraArticular Injection into the Knee Joint. Pharm. Res. 2013, 30 (1), 257268.

(38) Silva, R.; Ferreira, H.; Azoia, N. G.; Shimanovich, U.; Freddi, G.; Gedanken, A.; Cavaco-Paulo, A. Insights on the mechanism of formation of protein microspheres in a biphasic system. Mol. Pharmaceutics 2012, 9 (11), 3079-3088.

(39) Bhattacharjee, S. DLS and zeta potential - What they are and what they are not? J. Controlled Release 2016, 235, 337-351.

(40) Kokebie, R.; Aggarwal, R.; Lidder, S.; Hakimiyan, A. A.; Rueger, D. C.; Block, J. A.; Chubinskaya, S. The role of synovial fluid markers of catabolism and anabolism in osteoarthritis, rheumatoid arthritis and asymptomatic organ donors. Arthritis Res. Ther 2011, 13 (2), R50.

(41) Hoff, P.; Buttgereit, F.; Burmester, G. R.; Jakstadt, M.; Gaber, T.; Andreas, K.; Matziolis, G.; Perka, C.; Rohner, E. Osteoarthritis synovial fluid activates pro-inflammatory cytokines in primary human chondrocytes. International orthopaedics 2013, 37 (1), 145-151.

(42) Arruebo, M.; Valladares, M.; Gonzalez-Fernandez, A. AntibodyConjugated Nanoparticles for Biomedical Applications. J. Nanomater. 2009, 2009, 439389. 
(43) Solhjou, Z.; Uehara, M.; Bahmani, B.; Maarouf, O. H.; Ichimura, T.; Brooks, C. R.; Xu, W.; Yilmaz, M.; Elkhal, A.; Tullius, S. G.; Guleria, I.; McGrath, M. M.; Abdi, R. Novel Application of Localized Nanodelivery of Anti-Interleukin-6 Protects Organ Transplant From Ischemia-Reperfusion Injuries. Am. J. Transplant. 2017, 17 (9), 23262337.

(44) Holyoak, D. T.; Tian, Y. F.; van der Meulen, M. C.; Singh, A. Osteoarthritis: Pathology, Mouse Models, and Nanoparticle Injectable Systems for Targeted Treatment. Ann. Biomed. Eng. 2016, 44 (6), $2062-2075$. 